ABDI: Jurnal Pengabdian dan Pemberdayaan Masyarakat ISSN: 2656-369X (Print), 2684-8570 (Online)

Volume 1 No. 1, Juni 2019

http://abdi.ppj.unp.ac.id/index.php/abdi

Email: abdi@ppj.unp.ac.id

DOI: https://doi.org/10.24036/abdi/voll-issl/2

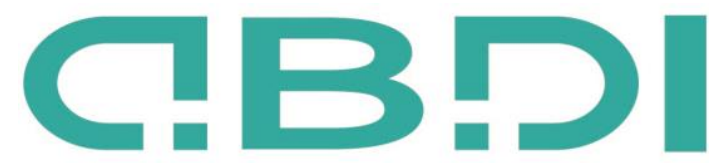

ABDI: JURNAL PENGABDIAN DAN PEMBERDAYAAN MASYARAKAT

\title{
Optimalisasi Institusi Pendidikan Sebagai Upaya Pengendalian Hoax
}

\author{
Reno Fernandes ${ }^{1}$, Eka Vidya Putra ${ }^{2}$, Rila Muspita ${ }^{3}$ \\ 1,2 Jurusan Sosiologi Universitas Negeri Padang \\ ${ }^{3}$ Jurusan Pendidikan Luar Biasa Universitas Negeri Padang \\ Email: renofernandes@ fis.unp.ac.id, ekavidyaputra@gmail.com
}

\begin{abstract}
Abstrak
Di Indonesia pengguna internet terbanyak adalah kelompok usia Sekolah. Untuk itu, membekali kelompok siswa dengan Pendidikan Literasi merupakan solusi untuk mengantisipasi penyebaran Hoax yang ditengah berkembang pesat dalam masyarakat. Meskipun kurikulum 2013 telah mengakomodir ide tentang literasi media, tetapi pada tataran pelaksanaannya masih belum dapat dilakukan oleh Guru. Literasi media adalah pendidikan yang mengajari khalayak media agar memiliki kemampuan menganalisis pesan media, memahami bahwa media memiliki tujuan komersial/bisnis dan politik sehingga mereka mampu bertanggungjawab dan memberikan respon yang benar ketika mendapatkan informasi dari media. Artikel ini disarikan dari pengabdian masyarakat yang penulis lakukan kepada khalayak sasaran Musyawarah Guru Mata Pelajaran Sosiologi. Sebagai organisasi Guru yang terorganisir dapat dimanfaatkan sebagai Agen dalam mengantisipasi penyebaran Hoax dikalangan siswa di Sumatera Barat. Artikel ini berisi tentang pengembangan pemahaman dan keterampilan kepada Guru tentang literasi media dan pelaksanaan pendidikan literasi yang terintegrasi dalam setiap materi pelajaran Sosiologi di SMA.
\end{abstract}

Kata kunci: Pendidikan, Literasi media, Hoax

\section{Abstract}

In Indonesia the most internet users are the School age group. For this reason, providing a group of students with Literacy Education is a solution to anticipate the spread of hoaxes that are growing rapidly in society. Although the 2013 curriculum has accommodated ideas about media literacy, the teacher still cannot do it at the level of implementation. Media literacy is education that teaches media audiences to have the ability to analyze media messages, understands that media has commercial / business and political goals so that they are able to be responsible and provide the right response when getting information from the media. This article is extracted from the community service that the writer did to the target audience of Sociology Subject Teacher Consultation. As an organized organization, the teacher can be used as an agent in anticipating the spread of hoaxes among students in West Sumatra. This article is about developing understanding and skills to the Teacher about media literacy and the implementation of literacy education that is integrated in every Sociology subject matter in high school.

Keyword: Education, Media Literacy, Hoax

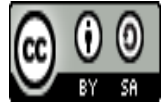

Received: 18 Maret 2019

Revised: 29 Maret 2019

Available Online: 10 April 2019

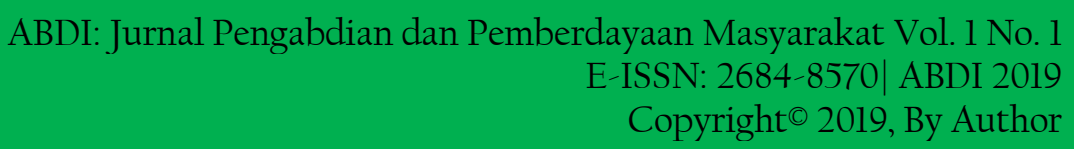




\section{Pendahuluan}

Data Survei yang dilakukan oleh Asosiasi Penyelenggara Jaringan Internet Indonesia (APJII) mengungkap bahwa lebih dari setengah penduduk Indonesia kini telah terhubung ke internet. Dimana 132,7 juta orang dari 256,2 juta orang penduduk Indonesia telah terhubung ke internet. Data lain menunjukkan usia 10-34 tahun adalah kelompok yang paling dominan dalam menggunakan internet. Data tersebut menyiratkan pengguna internet di isi oleh kelompok usia Sekolah.

Perkembangan penggunaan internet di Indonesia juga dapat dilihat dari konten yang ditelusuri di Internet. Hasil Survey APJII pada tahun 2017 menyatakan bahwa penggunaan akses internet terbanyak digunakan untuk Sosial Media, sebanyak 87,13 dan pengguna aplikasi Chating 89, $35 \%$ (APJJI, 2017). Data secara keseluruhan dapat dilihat dalam grafik dibawah ini.

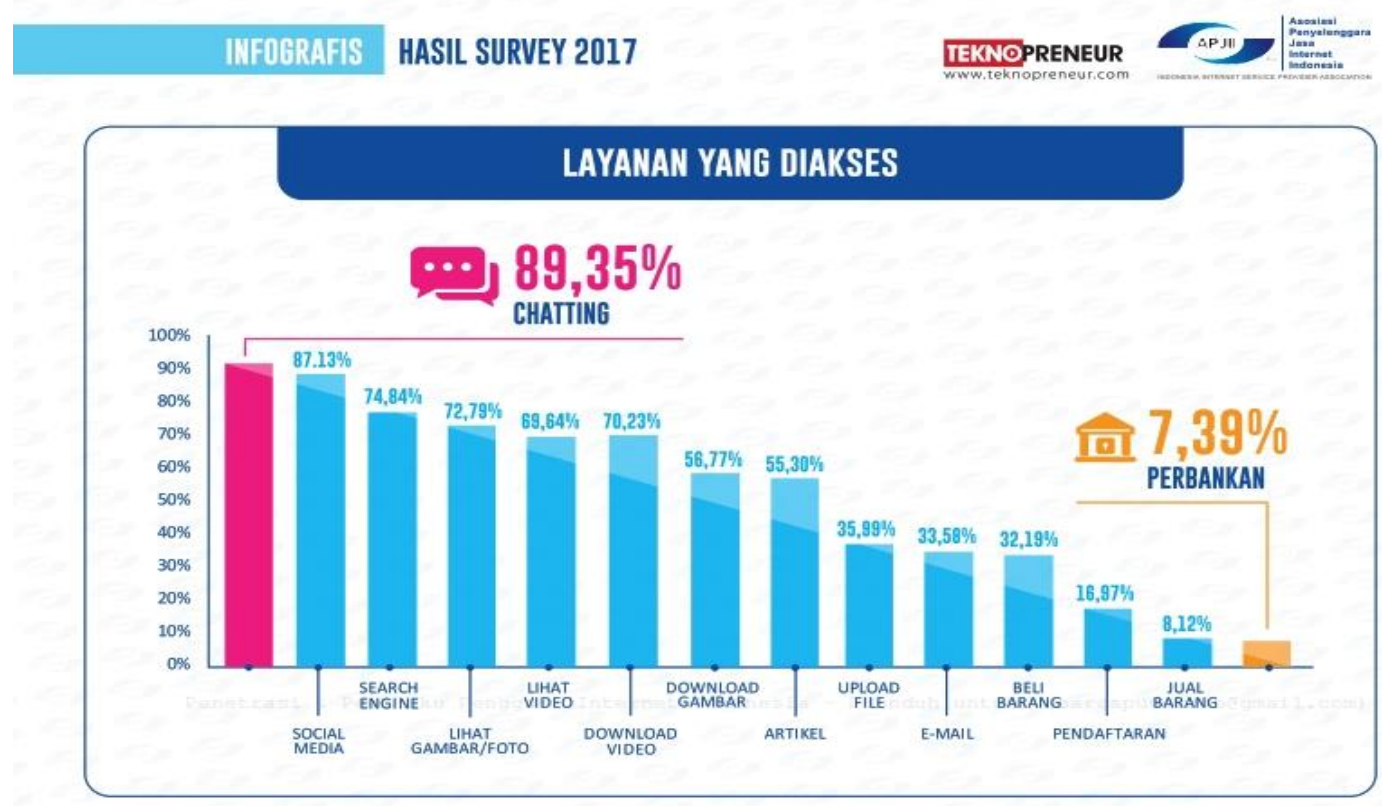

Gambar 1. Infografis Hasil Survey APJII

Sumber: Laporan Survey APJII 2017

Perkembangan teknologi informasi yang sangat pesat dan data tentang layanan tersebut bisa dimaknai secara positif, dimana masyarakat indonesia sudah memiliki tingkat melek teknologi informasi yang baik. Tetapi berdasarkan data layanan yang diakses, dimana sosial media dan aplikasi chating paling banyak digunakan, keadaan tersebut dikuatirkan dapat membawa dampak negatif yaitu permasalahan sosial baru. Salah satu dampak negatif tersebut adalah berkembangnya Penyebaran Hoax atau berita palsu melalui media sosial. Belakangan ini Hoax atau berita palsu menjadi konsen yang harus diselesaikan di Indonesia. penyebaran berita palsu yang tidak terkendali membawa dampak yang buruk untuk keteraturan sosial. Hoax dapat mendatangkan kegaduhan yang terjadi di media sosial yang bisa saja merambat ke dunia nyata. Perbincangan yang terdapat di media sosial berpotensi mengkonstruksi pemahaman publik mengenai suatu hal dalam kehidupan masyarakat.

Kegaduhan Di media sosial dapat berdampak dalam kehidupan nyata karena media sosial ini juga membentuk konstruksi pemaknaan tentang asumsi sosial kita (Juliswara, 2017).

Untuk itu, membekali kelompok usia muda dengan Pendidikan Literasi merupakan solusi untuk mengantisipasi penyebaran Hoax yang ditengah berkembang pesat dalam masyarakat. Literasi media adalah pendidikan yang mengajari khalayak media agar memiliki kemampuan menganalisis pesan media, memahami bahwa media memiliki tujuan komersial/bisnis dan politik sehingga mereka mampu bertanggungjawab dan memberikan respon yang benar ketika mendapatkan informasi dari media. 
Salah satu langkah melakukan pendidikan literasi media kepada siswa adalah berkolaborasi dengan Institusi Pendidikan dengan cara melakukan pengintegrasian literasi media dalam pembelajaran sebagai langkah untuk mengantisipasi penyebaran Hoax didalam masyarakat.

\section{Hasil dan Pembahasan}

\section{Institusi Pendidikan Sebagai Antisipasi Hoax}

Pendidikan adalah sebagai usaha sadar dan terencana untuk mewujudkan suasana belajar dan proses pembelajaran untuk peserta didik secara aktif mengembangkan potensi dirinya untuk memiliki kekuatan spiritual keagamaan, pengendalian diri, kepribadian, kecerdasan, akhlak mulia, serta keterampilan yang diperlukan dirinya dan masyarakat. Saat ini seperti yang termuat pada kurikulum 2013 Pendidikan Nasional dikembangkan dengan Penguatan Pendidikan Karakter sebagai bahagian terpenting pada pembentukan Kompetensi peserta didik. Salah satu yang terpenting dalam dunia pendidikan adalah proses pembelajaran yang dikelola oleh guru mata pelajaran peserta didik dapat berinternalisasi dengan banyak hal, sehingga proses tersebut memberikan sumbangan yang banyak dalam pembentukan karakter seseorang. Penguatan Pendidikan Karakter bangsa menjadi Program Utama Mendikbud 2015-2019 yaitu pengembangan ragam kurikulum sekolah berbasis kekuatan lokal dan peningkatan kapasitas sekolah (termasuk guru) dalam menerapkan Kurikulum Nasional dan mampu secara mandiri mengembangkan Kurikulum sekolah sesuai konteks kebutuhannya.

Terkait dengan permasalahan kemajuan teknologi informasi dimana telah mendatangkan masalah sosial baru yaitu penyebaran Hoax. Siswa adalah kelompok usia terbesar sebagai pengguna internet merupakan kelompok paling rentan mendapat akibat buruk dari penyebaran hoax tersebut. Untuk itu salah satu jalan untuk mengantisipasi dampak buruk dari penyebaran hoax adalah dengan berkolaborasi dengan institusi pendidikan. Maksudnya siswa harus diberi pemahaman tentang literasi media.

Pengintegrasian Literasi Media dalam pembelajaran merupakan hal yang paling mungkin dilakukan mengingat, dalam pembelajaran abad 21 yang menjadi program unggulan pemerintah telah memasukkan pendidikan literasi dan Keterampilan 4C (Communication, Collaboration, Critical Thinking and Problem Solving, dan Creativity and Innovation). ${ }^{1}$ dalam pembejaran yang hendak dicapai dalam setiap pembelajaran pada institusi pendidikan.

Selain itu, Keterampilan yang menjadi fokus kompetensi pembelajaran dalam kurikulum 2013 adalah keterampilan dalam menguasai media, informasi, dan teknologi (TIK). Keterampilan ini menghendaki siswa melek informasi, melek media, dan melek TIK. Kemampuan melek informasi mencakup keterampilan mengakses informasi secara efektif dan efisien, kompeten menilai dan mengkritisi informasi, dan kemampuan menggunakan informasi secara akurat dan kreatif. Keterampilan melek media mencakup kemampuan untuk menggunakan media sebagai sumber belajar dan menggunakan media sebagai alat untuk berkomunikasi, berkarya, dan berkreativitas. Keterampilan melek TIK mencakup kemampuan menggunakan TIK secara efektif baik sebagai alat penelitian, alat berkomunikasi, dan alat evaluasi serta memahami benar kode etik penggunaan TIK (Trilling \& Fadel, 2009).

\section{Pelatihan Integrasi Literasi Media dengan Pembelajaran}

Meskipun melalui kebijakan kurikulum 2013 telah mengakomodir ide tentang literasi media dan keterampilan $4 \mathrm{C}$, tetapi pada tataran pelaksanaannya masih belum dapat dilakukan oleh Guru dalam proses belajar mengajar. Dalam pelaksanaannya pada mata pelajaran tingkat SMA di Sumatera Barat guru masih berorientasi mengejar target pencapaian materi, tetapi belum mengembangkan kompetensi yang dimiliki peserta didik secara maksimal seperti tuntutan kurikulum. Di dalam kelas guru menjelaskan materi ajar, memberi contoh dan bukan meminta peserta didik mengekplorasi contoh dari fenomena yang ada disekitarnya, latihan soal dan kemudian memberi pekerjaan rumah (PR). Proses pembelajaran yang seharusnya dilaksanakan dalam pembelajaran juga tidak sepenuhnya dilaksanakan karena kemampuan guru mengembangkan desain pembelajaran sosiologi sesuai dengan tuntutan kurikulum mengenai Literasi masih terbatas. 
Solusi dari permasalahan diatas adalah dengan memberikan pelatihan kepada guru tentang Integrasi Literasi Media dengan pembelajaran. Agar pelatihan tersebut berlangsung efektif dan efisien maka jalur melakukan penelitian dengan melibatkan kelompok sasaran guru-guru yang tergabung didalam Musyawarah Guru Mata Pelajaran (MGMP).

Keberadaan MGMP sebagai sebuah organisasi Guru yang terorganisir dapat dimanfaatkan sebagai Agen dalam mengantisipasi penyebaran Hoax dikalangan siswa di Sumatera Barat. Upaya ini urgen dilakukan karena memberikan pemahaman kepada Guru tentang literasi media dan pelaksanaan pendidikan literasi yang terintegrasi dalam setiap materi pelajaran adalah hal yang sangat penting. Memberikan keterampilan kepada Guru Sosiologi tentang literasi media berarti kita akan berkontribusi menyebarkan pemahaman literasi media kepada lebih banyak orang yaitu Siswa sebagai kelompok dominan yang memanfaatkan media social dan kelompok yang akan mudah terpengaruh dengan Hoax atau Berita Palsu.

Adapun metode yang diperlukan adalah dengan memberikan seminar dan workshop diantaranya: Pertama, Seminar Literasi Media, Hoax dan Media Sosial. Seminar ini dilaksanakan dengan tujuan guru mendapatkan pengetahuan tentang Literasi Media, Hoax dan cara mengatisipasinya dengan berfikir ilmiah. Tahapan kedua, Seminar Mengenai pengintegrasian literasi media dengan matapelajaran, seminar ini bertujuan guru memahami cara mengintegrasikan keterampilan literasi media dengan matapelajaran yang diajarkannya.

Pengintegrasian literasi media yang dimaksud di atas adalah memasukkan nilai-nilai, pengetahuan dan keterampilan yang sesuai dengan materi pelajaran ke dalam proses pembelajaran melalui kompetensi dasar (KD) yang relevan pada mata pelajaran. Proses Integrasi diawali dengan menganalisis materi/bahan kajian pada setiap Kompetensi Dasar (KD).

Selanjutnya materi-materi tersebut dikaitkan dengan literasi media. Pengintegrasian lieterasi media diupayakan dapat menjadi motivasi dalam pembelajaran dan mempermudah pencapaian kompetensi peserta didik serta mengindari penambahan beban belajar.

Tujuan program integrasi literasi media pada mata pelajaran adalah untuk meningkatkan kompetensi Keterampilan 4C (Communication, Collaboration, Critical Thinking and Problem Solving, dan Creativity and Innovation). Hasil yang diharapkan dari pelaksanaan program integrasi lieterasi media ini pada mata pelajaran adalah: Meningkatnya kemampuan guru dalam penguasaan konsep berfikir ilmiah dan pendidikan literasi, Meningkatnya kompetensi guru merancang persiapan perangkat pembelajaran yang yang mengintegrasikan literasi media, Meningkatnya kemampuan guru mengembangkan proses pembelajaran yang mengintegrasikan lieterasi media. Meningkatnya pemahaman peserta didik terhadap literasi media dan mampu mengantisipasi penyebaran Hoax. Terwujudnya keterampilan peserta didik yang bisa mengantisipasi penyebaran Hoax.

\section{Kesimpulan}

Dalam menyikapi penggunaan teknologi informasi yang mendatangkan perkembangan Hoax atau berita palsu yang semakin masif terjadi di Indonesia akhir-akhir ini. Maka Siswa sebagai kelompok yang paling rentan mendapatkan dampaknya perlu diberikan pendidikan literasi media sebagai alat untuk mengantisipasinya. Cara menyebarluaskan pengetahuan dan keterampilan tersebut dilakukan dengan berkolaborasi dengan institusi pendidikan. Kolaborasi yang bisa dilakukan yaitu mengintegrasikan literasi media dengan matapelajaran yang ada disekolah. Upaya yang bisa dilakukan menyujudnya integrasi tersebut adalah dengan memberikan pelatihan pengintegrasian literasi media kedalam matapelajaran kepada guru yang tergabung didalam Majelis Guru Mata Pelajaran (MGMP). 


\section{Daftar Pustaka}

Laporan Hasil Survey Asosiasi Penyelenggara Jasa Internet Indonesia (APJII) tahun 2017

Trilling, B. \& Fadel, C. (2009). 21st Century Skills: Learningfor Life in Our Times. San Francisco: Jossey-Bass A Wiley Imprint. Hal 65

Undang undang no 20 tahun 2003 tentang sistem pendidikan nasional

Vibriza Juliswara. (2017). Mengembangkan Model Literasi Media yang Berkebhinnekaan dalam Menganalisis Informasi Palsu (Hoax) di Media Sosial. Jurnal Pemikiran Sosiologi, 4(2).

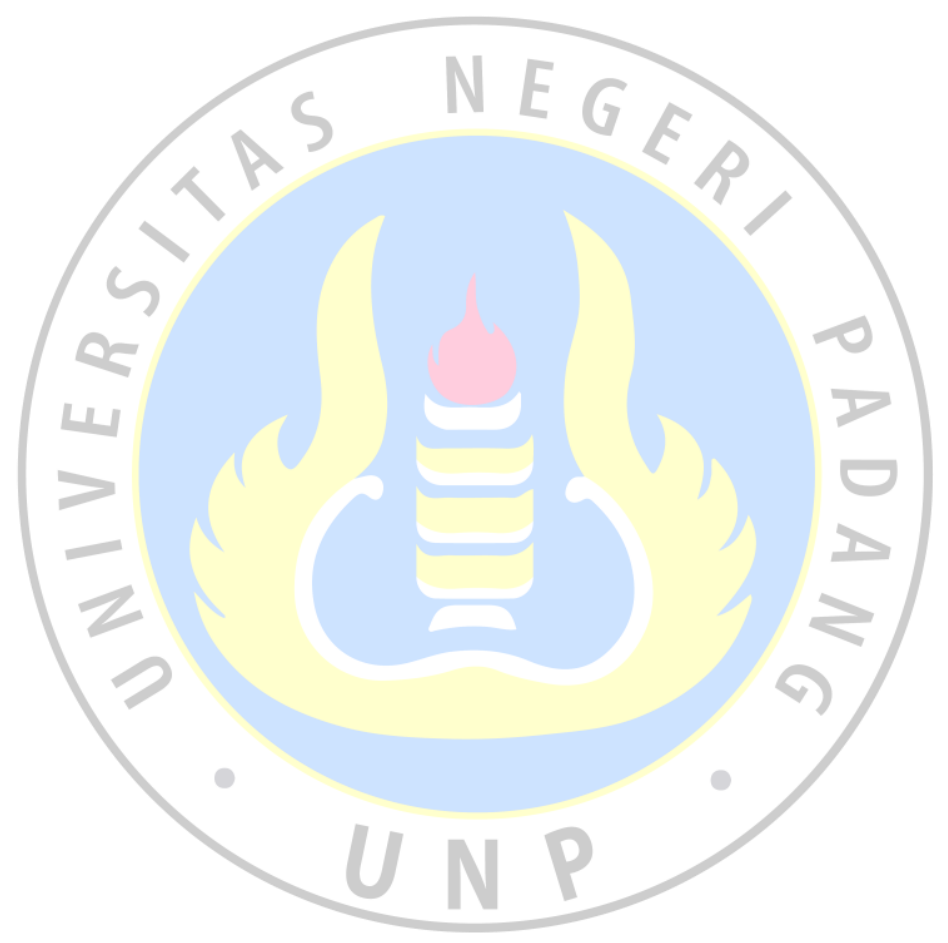

